\title{
Optimal Control of Matrix Converters
}

\author{
Andrea Formentini, Sabino Pipolo, Andrew Trentin, Pericle Zanchetta \\ Power Electronics, Machines and Control Group \\ University of Nottingham, Nottingham \\ Email: andrea.formentini@ nottingham.ac.uk
}

\section{Keywords}

$\ll$ Matrix converter», «Optimal control $\gg, \ll L Q R \gg$

\section{abstract}

In this paper a new control technique for matrix converter based on a Linear Quadratic Regulator (LQR) is proposed. Stabilization of matrix converter is often challenging due to the input filter resonance. The proposed method is compared with classical approaches for matrix converter control. It will be shown how the proposed approach can guarantee higher output current bandwidth providing also a good attenuation to grid disturbance.

\section{Introduction}

A matrix converter is a power converter capable of connecting two three phase systems directly to each other using a matrix of 9 bidirectional power switches. It offers different advantages compared to a standard back-to-back configuration like reduced size and weight, higher efficiency and better reliability due to the elimination of electrolytic capacitor used for DC-links. The system considered in this work is depicted in Fig. 1. It is composed by an input LC filter, the matrix converter and a RL as load. The former is used to prevent switching harmonics to finish directly into the grid.

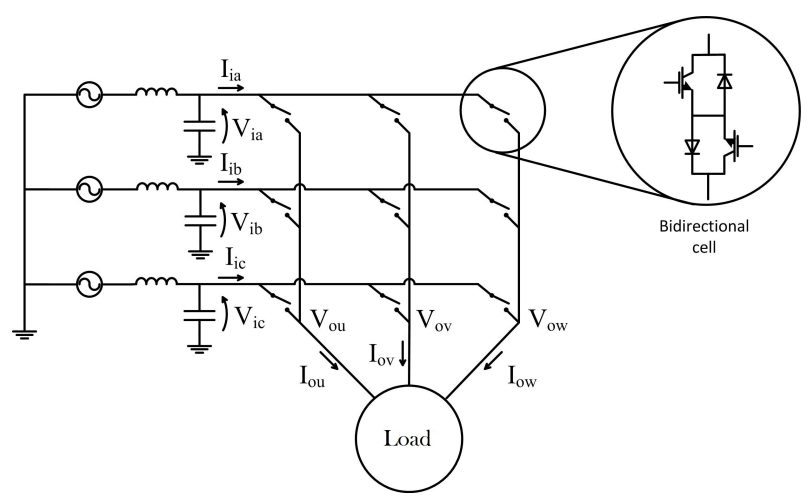

Fig. 1: System model.

Different control approaches have been proposed in literature. In $[1,2]$ authors propose to filter the measured input voltage $V_{i}$ with a low-pass filter before using it in the modulation process. In [3] the use of a high-pass filtered $V_{i}$ term added to the output reference voltage is used to increase system stability. In [4] Model Predictive Control is adopted.

In this work a new optimal control approach for regulation and stabilization of matrix converter is proposed. Compared to previously presented methods it offers a higher bandwidth and an active damping of the input filter resonance resulting in less oscillatory behaviour during transients. 


\section{Dynamic model}

The input filter of Fig. 1 can be be modelled in the dq-reference frame resulting in

$$
\begin{aligned}
& \dot{I}_{f d}=-\frac{R_{f}}{L_{t}} I_{f d}+\omega_{g} I_{f q}-\frac{1}{L_{t}} V_{i d}+\frac{1}{L_{t}} V_{g d} \\
& \dot{I}_{f q}=-\frac{R_{f}}{L_{t}} I_{f q}-\omega_{g} I_{f d}-\frac{1}{L_{t}} V_{i q}+\frac{1}{L_{t}} V_{g q} \\
& \dot{V}_{i d}=\frac{1}{C_{f}} I_{f d}+\omega_{g} V_{i q}-\frac{1}{C_{f}} I_{i d} \\
& \dot{V}_{i q}=\frac{1}{C_{f}} I_{f q}-\omega_{g} V_{i d}-\frac{1}{C_{f}} I_{i q}
\end{aligned}
$$

where $L_{t}=L_{f}+L_{g} . L_{f}, R_{f}$ and $C_{f}$ are inductance, resistance and capacitance of the input filter respectively. $V_{g}, L_{g}$ and $w_{g}$ are grid voltage, inductance and frequency while $I_{f}$ and $V_{i}$ are the inductor current and the capacitor voltage. Finally $I_{i}$ is the matrix converter input current. Hereafter subscripts $d$ and $q$ are used to identify quantities on the d-axis and q-axis respectively in the dq-reference frame.

Similarly, the RL load can be modelled in the dq-reference resulting in

$$
\begin{aligned}
& \dot{I}_{o d}=-\frac{R_{o}}{L_{o}} I_{o d}+\omega_{o} I_{o q}+\frac{1}{L_{o}} V_{o d} \\
& \dot{I}_{o q}=-\frac{R_{o}}{L_{o}} I_{o q}-\omega_{o} I_{o d}+\frac{1}{L_{o}} V_{o q}
\end{aligned}
$$

$R_{o}, L_{o}$ and $\omega_{o}$ are load resistance, inductance and output pulsation respectively while $I_{o}$ and $V_{o}$ are load current and matrix converter output voltage.

Input and output matrix converter currents are non-linearly related to each other as [2]

$$
\begin{gathered}
I_{i d}=\frac{V_{i d}\left(I_{o d} V_{o d}+I_{o q} V_{o q}\right)}{V_{i d}^{2}+V_{i q}^{2}} \\
I_{i q}=\frac{V_{i q}\left(I_{o d} V_{o d}+I_{o q} V_{o q}\right)}{V_{i d}^{2}+V_{i q}^{2}}
\end{gathered}
$$

Merging (1)-(3) a complete nonlinear dynamic model of the considered system is obtained.

\section{Controller design}

To design the controller, system equations (1)-(3) are firstly linearised about the equilibrium point resulting in the following linear system

$$
\dot{x}=A x+B u+G v
$$

where 


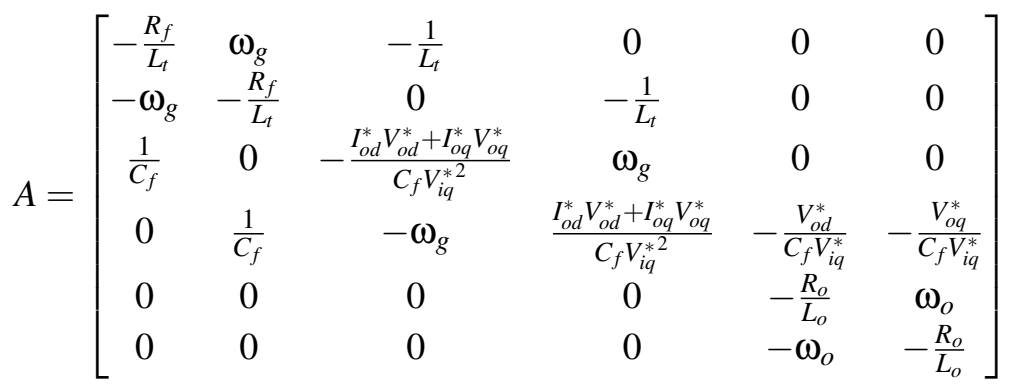

$$
\begin{aligned}
& B=\left[\begin{array}{cc}
0 & 0 \\
0 & 0 \\
0 & 0 \\
\frac{I_{o d}^{*}}{C_{f} V_{i q}^{*}} & \frac{I_{o q}^{*}}{C_{f} V_{i q}^{*}} \\
\frac{1}{L_{o}} & 0 \\
0 & \frac{1}{L_{o}}
\end{array}\right], \quad G=\left[\begin{array}{cc}
\frac{1}{L_{t}} & 0 \\
0 & \frac{1}{L_{t}} \\
0 & 0 \\
0 & 0 \\
0 & 0 \\
0 & 0
\end{array}\right]
\end{aligned}
$$

The superscript $*$ indicates the steady state values, assumed here as nominal values. The following assumptions have been made: $V_{i d}^{*}=V_{g d}^{*}=0, V_{i q}^{*}=V_{g q}^{*}$ and $I_{f d}^{*}=0$. State and input vectors are defined as:

$$
\begin{aligned}
& x=\left[\begin{array}{llllll}
I_{f d} & I_{f q} & V_{i d} & V_{i q} & I_{o d} & I_{o q}
\end{array}\right]^{\prime} \\
& u=\left[\begin{array}{ll}
V_{o d} & V_{o q}
\end{array}\right]^{\prime}, \quad v=\left[\begin{array}{ll}
V_{g d} & V_{g q}
\end{array}\right]^{\prime}
\end{aligned}
$$

System (4) has been subsequently discretized with Zero Order Hold ( $\mathrm{ZOH})$ method, resulting in

$$
x(k+1)=A_{d} x(k)+B_{d} u(k)+G_{d} v(k)
$$

This is necessary since the controller implementation will be discrete. When the bandwidth of the closed loop system approaches the sampling frequency, the discrete implementation of a stable controller designed in continuous domain can result in unstable modes. Finally system (9) has been extended with integral states to remove steady state error resulting in

$$
\tilde{x}(k+1)=\left[\begin{array}{cc}
A_{d} & 0 \\
-C_{d} & 0
\end{array}\right] \tilde{x}(k)+\left[\begin{array}{c}
B_{d} \\
0
\end{array}\right] u(k), \quad C_{d}=\left[\begin{array}{cccccc}
0 & 0 & 0 & 0 & 1 & 0 \\
0 & 0 & 0 & 0 & 0 & 1
\end{array}\right]
$$

where 0 represents a zero matrix of appropriate dimensions. $\tilde{x}=\left[\begin{array}{ll}x & x_{i}\end{array}\right]^{\prime}$ where $x_{i} \in \mathbb{R}^{2 \times 1}$ are the integral states used to remove steady state error between load currents and their references [5]. With the system in the form (10) it is possible to synthesise a LQR controller. The latter is defined as the control action $u$ that minimise the cost function

$$
J=\frac{1}{2} \sum_{k=0}^{\infty} x(k)^{\prime} Q x(k)+u(k)^{\prime} R u(k)
$$

where $Q \in \mathbb{R}^{8 \times 8}$ and $R \in \mathbb{R}^{2 \times 2}$ are the state and control weighting matrices respectively. It can be shown that this control actions results in a state feedback of the form

$$
u=K \tilde{x}=\left[\begin{array}{ll}
K_{S} & K_{i}
\end{array}\right] \tilde{x}
$$

where $K_{s} \in \mathbb{R}^{2 \times 6}$ and $K_{i} \in \mathbb{R}^{2 \times 2}$ are the state gains matrix and the integral gains matrix respectively.

As shown later, the proposed approach always return a stable controller and permits to obtain high 
bandwidth of the output current control loop without incurring in instability or oscillatory behaviour.

It is important to note that matrices (5) and (6) come from the linearisation of a nonlinear system. This implies they are state-dependant and a linearisation point must be selected before synthesizing LQR controller. A good choice is the nominal maximum output current that guarantee a stable system for $I_{o q} \in\left[0: I_{o q}^{n}\right]$. When the output current change sign however, controller must be synthesized again. Two different gain matrices $K$ have been computed linearising the system in $I_{o q}^{n}$ and $-I_{o q}^{n}$ respectively. The controller switches from one set of gains to the other according to output current sign.

\section{Tuning procedure}

One of the main disadvantage of LQR control approach is its counter-intuitive tuning. No direct relation between the weighting matrices $Q$ and $R$ and time or frequency domain performance indexes exists and often a trial and error approach is used. However, some simplification can be made and a simple tuning procedure derived. First of all, both matrices are usually set as diagonal matrices in order to have only quadratic terms in cost function (11). In this application there is not necessity, in general, to have different bandwidth on the $d$ and $q$ axis. For this reason matrix $R$ has been set equal to identity matrix. When the system is extended with integral states, it is convenient to weight only the latter in the cost function in order to ensure both a good reference tracking and disturbance rejection. For this reason $Q$ has been set

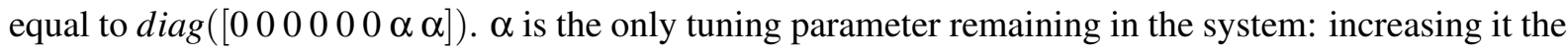
bandwidth of the output current controller increases and vice versa. Even if it is not possible to obtain a direct relation between $\alpha$ and the resulting bandwidth, with few attempts it is possible to synthesise the desired performance with the guarantee of getting always a stable and robust controller.

\section{Analysis and results}

The performance of the proposed control method is analysed using as example a $500 \mathrm{~kW}$ matrix converter supplying a RL load. All the system parameters are reported in Table I, where superscript ${ }^{n}$ denotes nominal values.

Table I: System parameters

\begin{tabular}{|c|c|c|}
\hline$L_{t}$ & 20 & {$[\mu H]$} \\
\hline$R_{f}$ & 4 & {$[\mathrm{~m} \Omega]$} \\
\hline$C_{f}$ & 300 & {$[\mu \mathrm{F}]$} \\
\hline$\omega_{g}$ & 50 & {$[\mathrm{~Hz}]$} \\
\hline$V_{g}^{n}$ & 240 & {$\left[V_{r m s}\right]$} \\
\hline$L_{o}$ & 100 & {$[\mu \mathrm{H}]$} \\
\hline$R_{o}$ & 0.23 & {$[\Omega]$} \\
\hline$I_{o q}^{n}$ & 1200 & {$[\mathrm{~A}]$} \\
\hline$\omega_{o}$ & 651 & {$\left[\frac{r a d}{s}\right]$} \\
\hline$P_{o}$ & 500 & {$[\mathrm{~kW}]$} \\
\hline
\end{tabular}

To better appraise the advantage of proposed method, it has been compared with the PI-based approach presented in $[1,2]$. These works propose to low-pass filter the input capacitor measured voltage $V_{i}$ before using it in the modulation process. This strategy has a double effect on the system: a lower low-pass filter cut-off frequency results in a more stable system but also in a higher distortion of load current due to grid higher harmonics.

\section{Output current bandwidth}

In [1] a standard Proportional Integral (PI) controller is also used to regulated load currents. $V_{i}$ low-pass filter cut-off frequency $\omega_{f}$ and PI bandwidth $\omega_{c}$ define the stability region of the system, as shown in Fig. 2. The figure clearly shows that the two parameters are inversely proportional to obtain a stable system. In addition, it is not possible to obtain an output current bandwidth higher that about $560 \mathrm{~Hz}$, no matter which $V_{i}$ filter cut-off frequency is used. On the other hand, using the control method proposed in this work, the output bandwidth can be set arbitrary high, limited only by sensors noise. 


\section{Grid distortion rejection}

The grid can be affected by high harmonics distortion. In the matrix converter, the absence of a DC stage cause the propagation of this disturbance directly to the load. The full state feedback controller in (12) produce a direct coupling between the grid side variables and the voltage applied to the load. However the attenuation of grid disturbance is still comparable to a standard PI control approach as shown in Fig. 3.

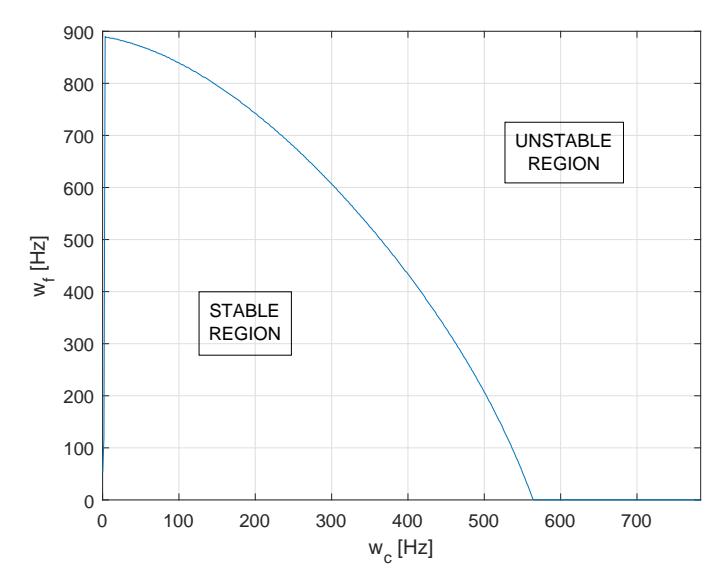

Fig. 2: Stability region for control approach proposed in $[1,2] . \omega_{f}$ and $\omega_{c}$ are $V_{i}$ low-pass filter and current controller bandwidths respectively.

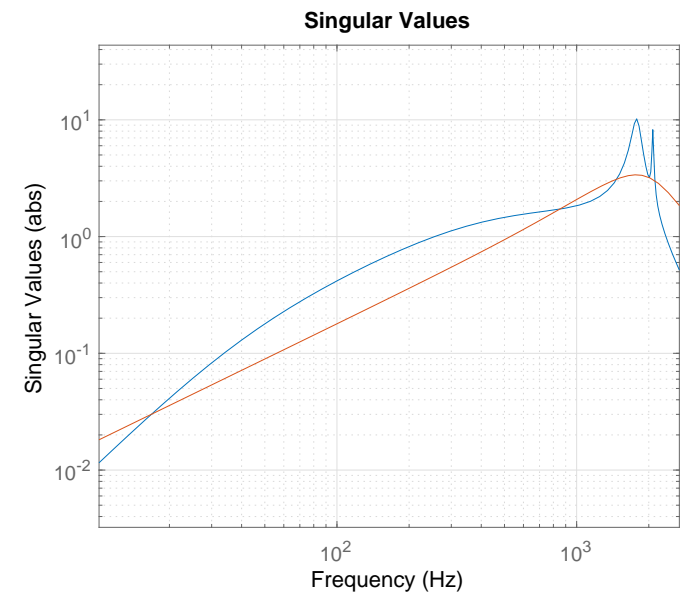

Fig. 3: Biggest singular value of the transfer function matrix from grid voltages disturbance to load currents. Blue: PI-based controller. Red: LQR controller.

LQR controller presents an attenuation of $0.55 \frac{V}{A}$ and $1.16 \frac{V}{A}$ at $300 \mathrm{~Hz}$ and $600 \mathrm{~Hz}$ respectively. In comparison, PI-based control shows an attenuation of $1.12 \frac{V}{A}$ and $1.55 \frac{V}{A}$ at the same frequencies. In this test and in all simulation results that follow the PI-based controller has been tuned assuming $\omega_{f}=40 \mathrm{~Hz}$ and $\omega_{c}=550 \mathrm{~Hz}$. Regarding LQR controller, $\alpha=1 \mathrm{e} 8$ is selected resulting in an output current bandwidth of $1.6 \mathrm{kHz}$.

\section{Simulation results}

The two control methods have been compared in simulations using Matlab Simulink. In all simulation a standard Venturini modulator is used [6] with a switching frequency of $10 \mathrm{kHz}$.
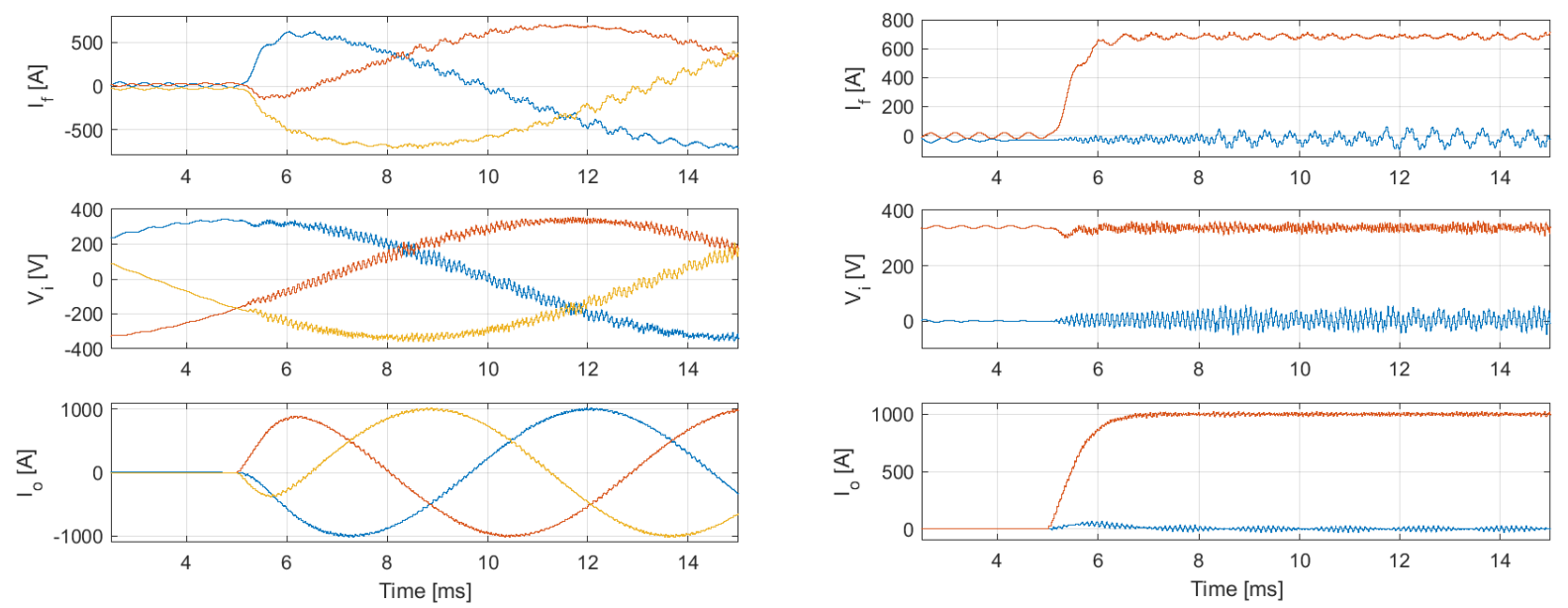

Fig. 4: Output current transient response using PI-based control method. 

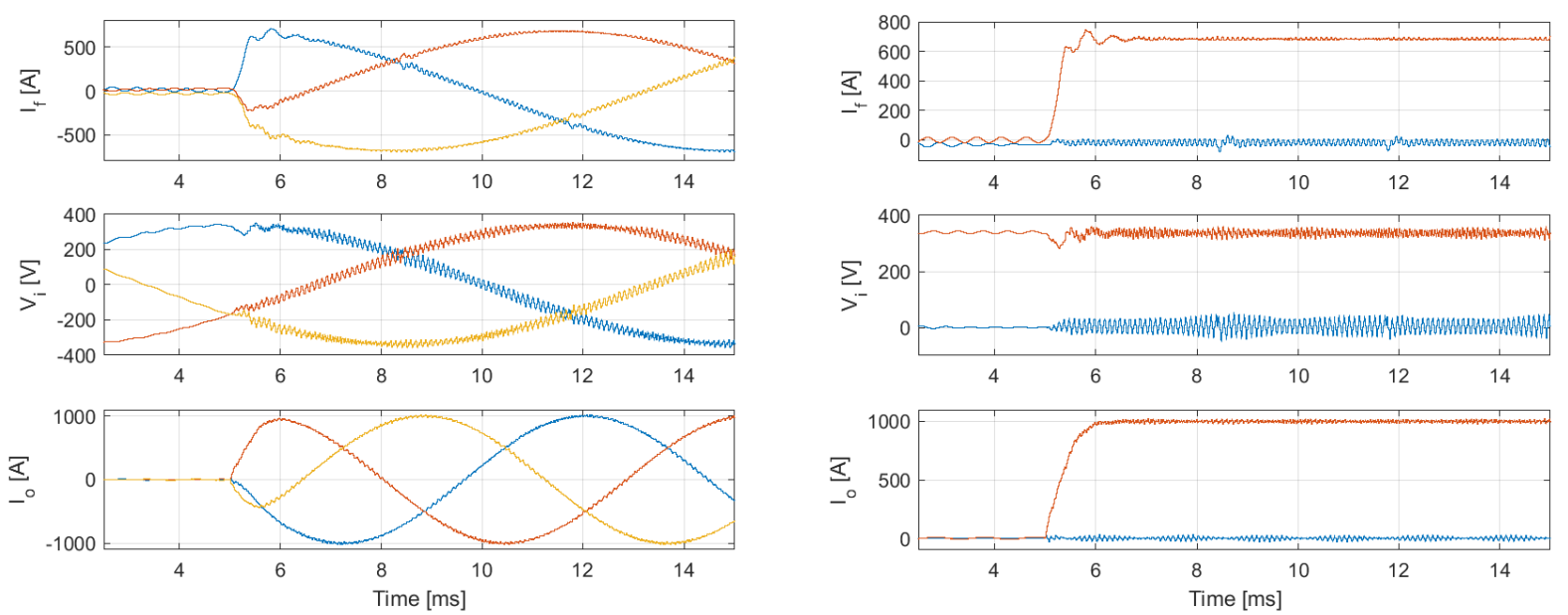

Fig. 5: Output current transient response using LQR control method.
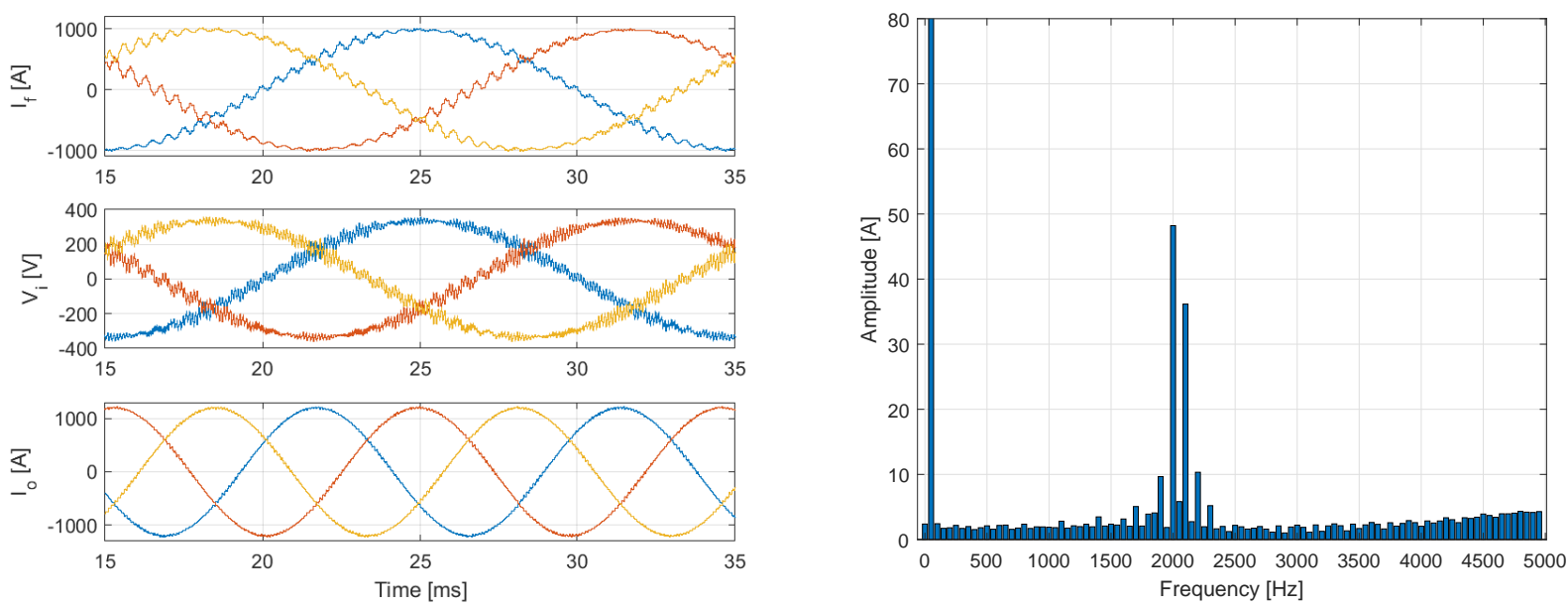

Fig. 6: PI-based control steady state response at nominal power. Left: Time domain response. Right: Phase A input current FFT.
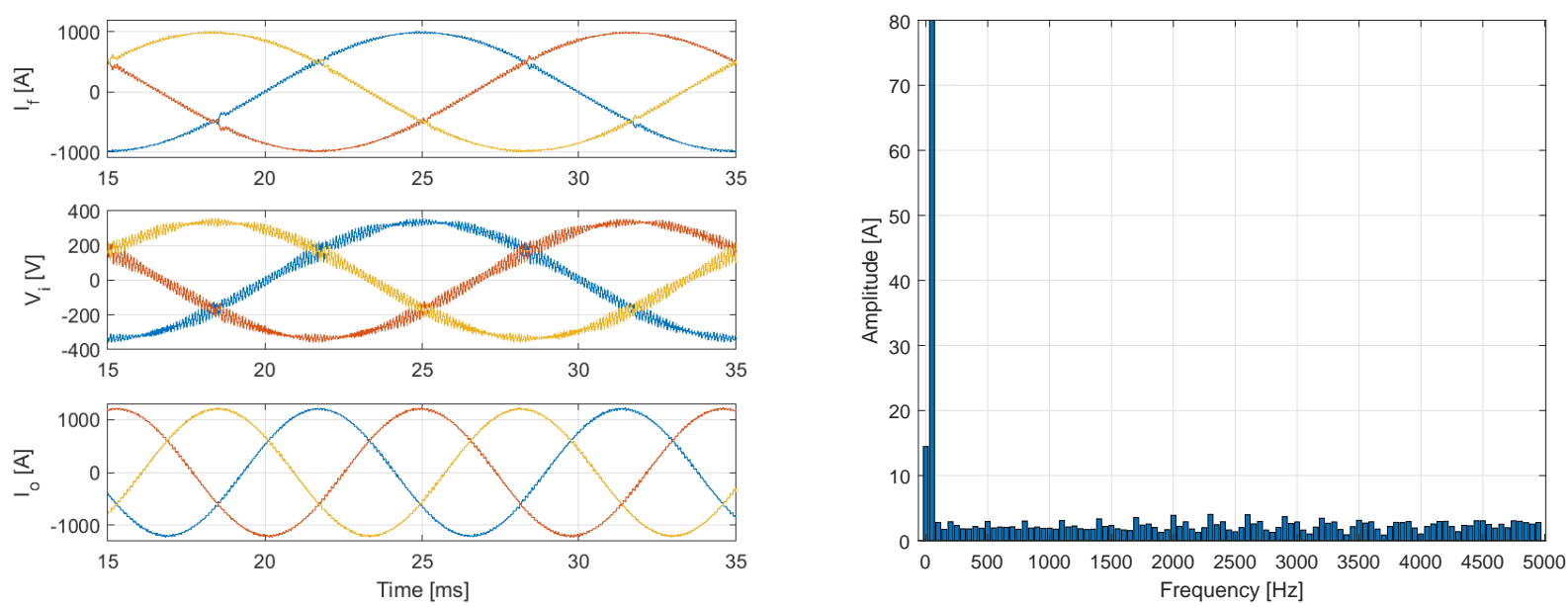

Fig. 7: LQR control steady state response at nominal power. Left: Time domain response. Right: Phase A input current FFT. 

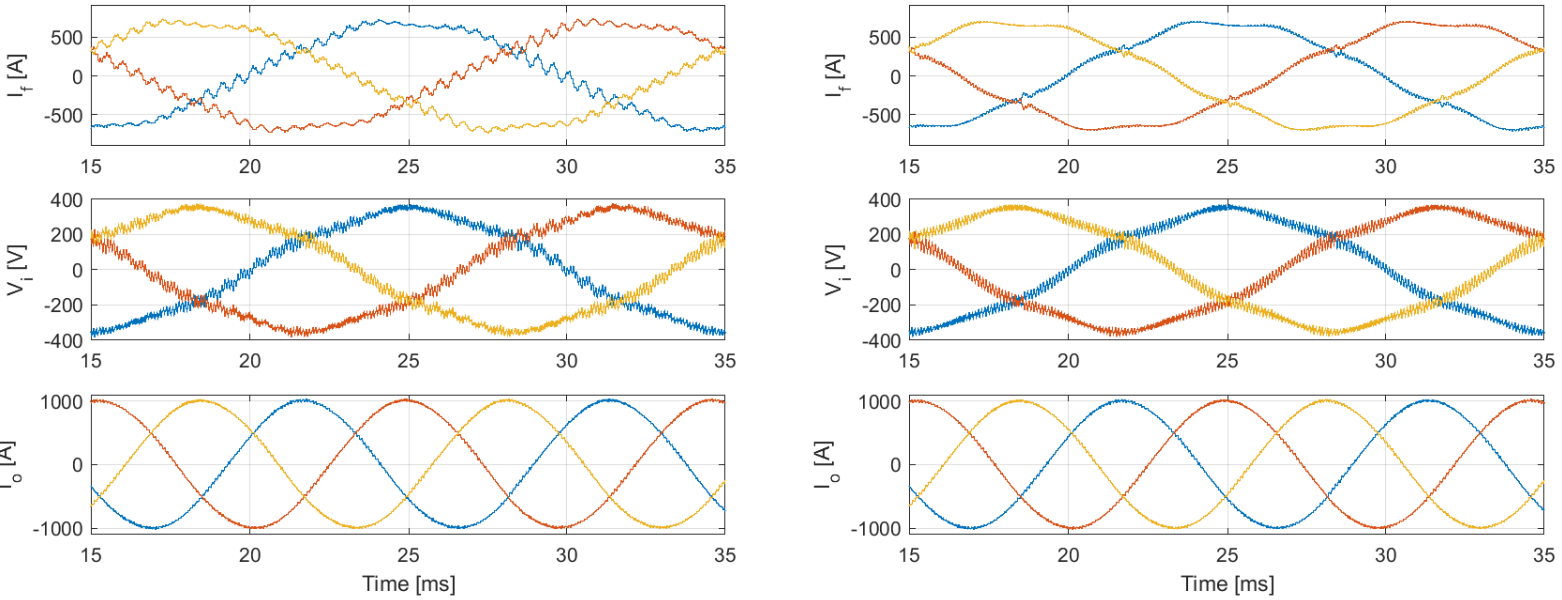

Fig. 8: Steady state system response to grid distortion. Left: PI-based controller. Right: LQR controller.
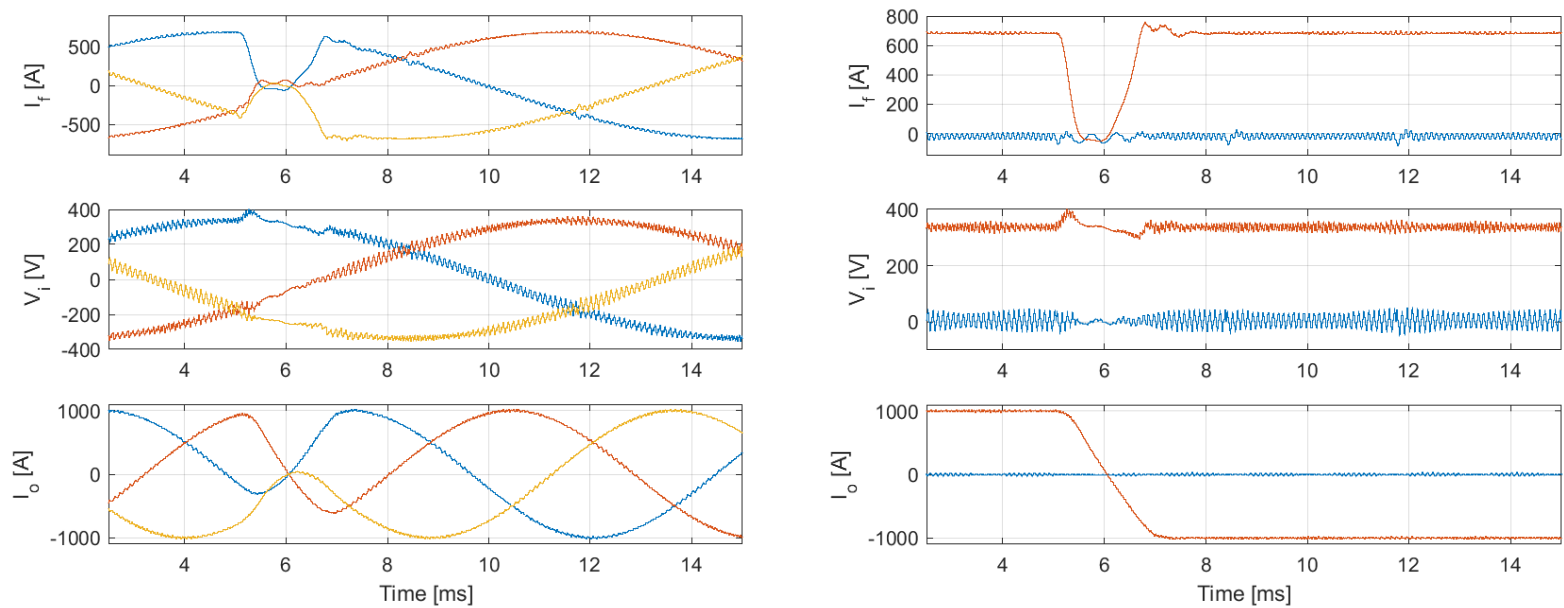

Fig. 9: LQR controller performance during output current inversion. Left: abc response. Right: dq response.

Fig. 4 and Fig. 5 show a current transient response from $0 \mathrm{~A}$ to $1200 \mathrm{~A}$ at $\mathrm{t}=5 \mathrm{~ms}$ using PI-based control method and proposed LQR method respectively. The output frequency is set to $\omega_{o}=651 \frac{\mathrm{rad}}{\mathrm{s}}$. As can be noted the proposed controller presents a faster dynamic response because it allows to be tuned for an higher output current bandwidth. In addition, it is able to damp far quickly oscillations caused by input filter resonance. This can be better appreciated in Fig. 6 and Fig. 7 that show the steady state behaviour of the two analysed controllers at system nominal power. Input currents Total Harmonic Distortion (THD) are $6.63 \%$ and $2.37 \%$ for PI-based and LQR controller respectively. The main reason for a higher THD in PI-based control are harmonics around $2000 \mathrm{~Hz}$, the input filter resonance frequency as can be noted from FFT in Fig. 6.

A test is also performed to evaluate the robustness to grid distortion. Fig. 8 shows the steady state response of the two analysed control approaches to a $5 \% 5^{\text {th }}$ harmonic grid distortion. The output current THDs are $2.18 \%$ and $2.0 \%$ for PI-based control and LQR control respectively. It demonstrates that the output current distortion due to grid harmonics is comparable in the two cases. Finally, Fig. 9 shows LQR controller performance when a output current reference step from $1000 \mathrm{~A}$ to $-1000 \mathrm{~A}$ is applied at $5 \mathrm{~ms}$. As can be noted when d-axis output current change sign the matrix gain is changed without creating any distortion. With this approach the proposed controller can guarantee system stability in the whole nominal range. 


\section{Conclusions}

This paper presents a new LQR-based control approach for matrix converter. It has been shown how the proposed method allows higher output current bandwidth compared to traditional PI-based control approaches. In addition a better damping on the input filter resonance is obtained resulting in a lower grid current THD. Finally the proposed approach has been test in the whole operative range along with in presence of grid distortion showing very good results.

\section{References}

[1] D. Casadei, G. Serra, A. Tani, and L. Zarri, "Effects of input voltage measurement on stability of matrix converter drive system," IEE Proceedings - Electric Power Applications, vol. 151, no. 4, pp. 487-497, July 2004.

[2] D. Casadei, G. Serra, A. Tani, A. Trentin, and L. Zarri, "Theoretical and experimental investigation on the stability of matrix converters," IEEE Transactions on Industrial Electronics, vol. 52, no. 5, pp. 1409-1419, Oct 2005.

[3] Y. Sun, M. Su, X. Li, H. Wang, and W. Gui, "A general constructive approach to matrix converter stabilization," IEEE Transactions on Power Electronics, vol. 28, no. 1, pp. 418-431, 2013.

[4] A. Formentini, L. De Lillo, M. Marchesoni, A. Trentin, P. Wheeler, and P. Zanchetta, "A new mains voltage observer for PMSM drives fed by matrix converters," in 16th European Conference on Power Electronics and Applications, 2014, pp. 1-10.

[5] G. F. Franklin, J. D. Powell, and M. L. Workman, Digital control of dynamic systems. Addisonwesley Menlo Park, CA, 1998, vol. 3.

[6] A. Alesina and M. G. Venturini, "Analysis and design of optimum-amplitude nine-switch direct ac-ac converters," IEEE Transactions on Power Electronics, vol. 4, no. 1, pp. 101-112, 1989. 